Running head: Identity processes and interpersonal relations

\title{
Identity processes, threat and interpersonal relations: accounts from British Muslim gay men
}

\author{
Rusi Jaspal* \\ University of Nottingham \\ Marco Cinnirella \\ Royal Holloway, University of London
}

Citing this article:

Jaspal, R. \& Cinnirella, M. (in press). Identity processes, threat and interpersonal relations: accounts from British Muslim gay men. Journal of Homosexuality.

Correspondence: Rusi Jaspal, Institute for Science and Society, School of Sociology and Social Policy, University of Nottingham, Nottingham NG7 2RD, United Kingdom. Tel: +44

(0)115 9515413 Fax: +44 (0)115 8466349

*e-mail rusi.jaspal@gmail.com

Acknowledgements: The authors would like to thank the anonymous reviewers who provided useful and constructive feedback on an earlier version of this paper. 


\title{
Identity processes, threat and interpersonal relations: accounts from British Muslim gay men
}

\author{
Rusi Jaspal \\ University of Nottingham
}

\author{
Marco Cinnirella \\ Royal Holloway, University of London
}

\begin{abstract}
This study explores identity processes, identity threat and interpersonal relations with other gay men in a qualitative interview study with a sample of young British Muslim gay men (BMGM) of Pakistani background. Transcripts were subjected to qualitative thematic analysis. Data were analysed through the interpretive lens of identity process theory (IPT). Three superordinate themes are reported: (i) "self continuity and the transition from straight to gay space"; (ii) "interpersonal relations with other gay men and self-/other-categorisation"; and (iii) "interpersonal contact/ identification with White gay men as an identity enhancer". Theoretical and practical implications of the results are discussed.
\end{abstract}

Keywords: gay identity; homosexuality; identity threat; interpersonal relations; identity process theory; Muslims; social psychology; qualitative.

In recent years there has been increased academic attention to the interface of sexual and religious identities. It has been recognised that gay and lesbian individuals with religious faith generally face greater social and psychological challenges as a result of their identity configuration. Social scientists have studied, to varying degrees, the intersection of these identities among gay Christians (e.g. Wilcox, 2003; Yip, 1997), gay Jews (Balka \& Rose, 1989; Coyle \& Rafalin, 2000) and, more recently, gay Muslims (Jaspal \& Cinnirella, 2010a; Jaspal \& Siraj, in press; Minwalla et al., 2005; Yip, 2005, 2007). This has filled an important lacuna in the literature, since it is generally accepted that socio-cultural processes play a fundamental role in the construction of gay identity, and that sexual identity intersects with other identity dimensions of the self-concept, such as religious and ethnic identities (Eliason, 1996). While the interface of sexual and religious identities among Muslim gay men has been explored in some depth by sociologists, anthropologists and cultural theorists, there is little existing socio-psychological research into identity among British Muslim gay men (BMGM; Jaspal \& Cinnirella, 2010a; Jaspal \& Siraj, in press). This scarcity is unfortunate given social psychology's long tradition of studying categorisation, identity processes and identity threat (Breakwell, 1986; Verkuyten, 2005). It is argued that these heuristic tools are required to make sense of identity experiences among BMGM. The present paper explores the socio-psychological implications of BMGM's self-inclusion in gay affirmative social contexts, with particular attention to identity processes and interpersonal relations with sexual, religious and ethnic ingroup and outgroup members.

\section{Homosexuality in Islam}

Islam gives 'hegemonic status to heterosexuality' (Yip, 2004, p. 297). This is understandable given that the major ideological channels of communication, such as Islamic holy scripture (the Koran), Islamic law (Shari'ah), and the verbal teachings of the Prophet Mohammed (Ahadith) explicitly outlaw homosexuality (Bouhdiba, 1998). The overt rejection of homosexuality in Islam stems from the story of Lut ('Lot' in Hebrew) in the Quran, which has been widely interpreted as 
God's condemnation of homosexuals (Jamal, 2001). It has been argued that 'Islam's explicit condemnation of homosexuality has created a theologically based homophobia which engenders the intolerance of homosexuals by Muslims' (Siraj, 2009, p. 41). In light of such intolerance at the institutional level, it is unsurprising that social representations of homosexuality remain negative within the Muslim community (Green \& Numrich, 2001). In fact, Siraj (2009, p. 49) argues that even the most educated sections of the Muslim community can hold deeply homophobic attitudes, exhibiting 'repulsion and disgust towards homosexuality'. Crucially, she identifies religiosity as being conducive to homophobic prejudice. Although it is acknowledged that religiosity can be a predictor of homophobic prejudice among Christians in North America as well (e.g. Rayside \& Wilcox, 2011), it is reasonable to assume that the cultural processes of heteronormativity and compulsory heterosexuality are acutely active in Islamic religious contexts (Boellstorff, 2005; Kligerman, 2007). Consequently, sexuality may be considered a particularly threatening dimension of identity among BMGM (Jaspal \& Cinnirella, 2010a).

\section{Identity processes and identity threat}

Given the scope for stigmatisation and identity threat in the BMGM experience, the theoretical approach employed in this paper is derived from identity process theory (IPT; Breakwell, 1986, 1988, 1992, 1993, 2001). IPT proposes that the structure of identity should be conceptualised in terms of its content and value/ affect dimensions and that this structure is regulated by two universal processes, namely the assimilation-accommodation process and the evaluation process. The assimilation-accommodation process refers to the absorption of new information in the identity structure and of the adjustment which takes places in order for it to become part of the structure. The evaluation process confers meaning and value upon the contents of identity.

Breakwell $(1986,1992)$ identifies four identity principles which guide these universal processes, namely continuity across time and situation, uniqueness or distinctiveness from others, feeling confident and in control of one's life and feelings of personal worth or social value. IPT refers to these, respectively, as continuity, distinctiveness, self-efficacy and self-esteem. Extending IPT, Vignoles and colleagues (Vignoles, Chryssochoou \& Breakwell, 2002; Vignoles, Regalia, Manzi, Golledge \& Scabini, 2006) have proposed two additional identity 'motives', namely belonging, which refers to the need to maintain feelings of closeness to and acceptance by other people, and meaning, which refers to the need to find significance and purpose in one's existence. Moreover, Jaspal and Cinnirella (2010a) propose the psychological coherence principle, which refers to the need for perceived compatibility and coherence between inter-connected identities in their self-concept. This principle is of particular relevance to BMGM given the scope for conflict between sexual and religious identities. IPT suggests that when any of these identity principles are obstructed by changes in the social context, for instance, identity is threatened and the individual will engage in coping strategies to alleviate the threat. A coping strategy is defined as 'any activity, in thought or deed, which has as its goal the removal or modification of a threat to identity’ (Breakwell, 1986, p. 78).

IPT has received considerable empirical support in work on gay and lesbian identity among various different research populations (Coyle, 1991; Coyle \& Rafalin, 2000; Jaspal \& Cinnirella, 2010a; Markowe, 2002). For the purposes of the present study, the major credentials of IPT lie in its ability to predict identity threat under specific socio-psychological conditions, as well as the various phases in coping, which are to be expected as a result of identity threat. Furthermore, IPT provides an integrative and flexible socio-psychological framework for understanding coping strategies at various levels of human interdependence (i.e. intrapsychic, interpersonal and intergroup). However, it is noteworthy that while much IPT research focuses upon identity threat, the theory also provides a comprehensive framework outlining the structure and processes of identity and the social matrix, in which identity is constructed (Breakwell, 1986). In contrast to the aforementioned IPT studies on LBGT identities, which identify what threatens 
identity and how individuals subsequently cope with threat, the present study employs the theory in order to enhance our understanding how identity processes can shape interpersonal relations among BMGM.

\section{Identity threat and coping strategies among BMGM}

Given that Muslims generally consider religious identity to constitute the over-arching 'core' identity within the self-concept (Ghuman, 1994; Jacobson, 1997; Jaspal \& Cinnirella, 2010a; Modood et al., 1997), strategies for coping with identity conflict, such as compartmentalism or departure from the religious group, are unlikely to be as effective among BMGM as they are said to be among gay men of other ethno-religious groups (e.g. Coyle \& Rafalin, 2000; Phellas, 2005). Instead BMGM may seek to re-interpret or re-construe the reasons for occupying the sociopsychological position of being gay and Muslim, which is said to constitute an effective intrapsychic strategy for alleviating identity threat (Breakwell, 1986). For example, Jaspal and Cinnirella (2010a) note that, given the threats to psychological coherence, BMGM may attribute the causality of their sexuality to external sources, such as to God, Satan or 'British national culture'. Indeed, this enabled some participants to construe their identities in positive terms (as God's creation), and compelled others to construe it in negative terms (at a Satanic attempt to deviate them from the 'correct' path). This may reduce the perception of identity conflict among BMGM.

The identity conflict associated with being gay and of religious faith may lead some individuals to take draconian measures to ensure the principled operation of identity processes. In their study on Jewish gay men, Coyle and Rafalin (2000) describe how some of their participants engaged in a variant of the isolation strategy, whereby the threatened individual isolates himself or herself in order to avoid further threats at the interpersonal level (see Breakwell, 1986). The activation of this strategy was intended to minimise feelings of rejection, exclusion and negative distinctiveness associated with being gay in a heteronormative context. IPT suggests that, while isolation may function as a transient coping strategy, it is likely to be conducive to poor psychological well-being in the long run (see Breakwell, 1986).

The recent formation of support group specifically for Muslim gay men, such as Imaan in the UK and Al-Fatiha in the USA, encourages integration rather than isolation. Affiliation in such organisations could be regarded in terms of an intergroup coping strategy. Indeed, Breakwell (1986) highlights the positive impact that 'social and informational networks' and 'consciousnessraising or self-help groups' can have for threatened individuals. One such benefit is the scope for 'theological capital' afforded to BMGM by virtue of their affiliation in gay affirmative support groups (Yip, 2007). This essentially allows members to re-construe holy scripture in a gay affirmative manner. In IPT terms, the intergroup strategy of group support facilitates the intrapsychic strategy of re-construal and re-conceptualisation, since individuals are empowered to re-construe identity-threatening aspects of the social context. However, it has also been found that some BMGM may be unwilling to re-construe holy scripture due to the ensuing threats to the continuity principle of identity (Jaspal \& Cinnirella, 2010a). Thus, aspects of the social context, which are closely associated with salient identities, may be more resistant to change.

Although group support is said to constitute one of the most effective coping strategies, BMGM are willing to partake in such group mobilisation. This may be explained by the notion that in many Muslim communities homosexuality among young men may be overlooked provided one avoids any public recognition of one's sexuality and fulfils social and religious obligations such as marriage (Murray, 1997). However, those BMGM who enter gay affirmative social contexts contravene this implicit social condition regarding homosexuality.

\section{BMGM in gay affirmative social contexts}


An additional component of the present study explores participants' reported experiences of participating in gay affirmative social contexts (GASC). GASC refers to those social spaces dominated by gay people and in which gay identity is regarded in positive or neutral, rather than negative, terms (e.g. nightclubs, bars, social groups). Prima facie, BMGM's involvement in GASC may reflect the group support strategy of enhancing identity, since it facilitates interpersonal contact with sexual ingroup members and exposure to relatively positive social representations regarding what it means to be gay in contemporary Britain.

In principle, one might assume that GASC would provide BMGM with opportunities to re-construe their gay identities in positive terms. Homosexuality is no longer depicted as a negative trait, but rather as a shared, prototypical self-aspect underlying a common collective ingroup identity (Gaertner \& Dovidio, 2000; Simon, 2004). This notion is reflected in a study of Cypriot gay men in London (Phellas, 2005), as some participants were said to perceive greater feelings of closeness to, and acceptance by, other non-Cypriot gay men than Cypriot heterosexual men. From an IPT perspective, this suggests that the belonging principle of identity may be more readily enhanced in GASC with other sexual ingroup members rather than in contexts in which ethno-religious identity is salient (Vignoles et al., 2006). However, the re-construal of one's 'gayness' in terms of an identity rather than in terms of a potentially mutable behaviour may, in turn, pose threats to identity at the intrapsychic level. The perception of being gay in terms of an immutable identity, that is, a constituent element of the self-concept may re-ignite the dormant threats to psychological coherence, given the renewed conflict between two identities, religious and sexual (see Jaspal \& Cinnirella, 2010a).

However, in the absence of empirical research examining BMGM's first-hand experiences in GASC, it is unclear precisely how these experiences might impact identity processes within this population in particular. As reported in Phellas' (2005) study, the social networking opportunities afforded by participation in GASC may have positive outcomes for the belonging principle of identity among BMGM. Indeed, Yip (2007, p. 86) observes that the construction of 'social capital' in this way offers 'an environment for the establishment of resources, networks, relationships, norms, meanings, and trust that enable smooth social engagements among members'. However, it must be acknowledged that overt preference of gay secular space to heterosexual religious space may be impossible for BMGM many of whom are deeply committed to their Muslim faith (Jaspal \& Cinnirella, 2010a).

GASC may allow individuals temporary social and psychological departure from negative social representations of homosexuality, which are prevalent in their heteronormative ethno-religious contexts. Exposure to positive representations disseminated in these contexts is likely to benefit self-esteem, since such representations encourage 'a positive conception of oneself' (Gecas, 1982, p. 20).

An important caveat is that having an atypical identity configuration (i.e. selfidentification as gay and Muslim) may expose BMGM to potential prejudice from secular gay men, who themselves may question the logic and coherence of identification as gay and Muslim (Abraham, 2009, 2010; Yip, 2007). This may result in the positioning of the BMGM as an ingroup 'black sheep' (Marques, Yzerbyt \& Leyens, 1988), which may constitute a significant setback for BMGM seeking to establish a sense of belonging in GASC. In a study on Muslim gay men in North America, Minwalla et al. (2005, p. 121) highlight the importance of 'race' in 'social dynamics within white gay culture'. They argue that non-white Muslim gay men may feel excluded from 'gay social dynamics', and that active participation in 'white gay culture' may, conversely, be regarded in terms of disloyalty by other non-White gay men (Minwalla et al., 2005, p. 122). As mentioned above, this can entail multiple threats to the belonging principle of identity, since individuals may feel rejected by their sexual ingroup due to 'race' or religious affiliation, as well as by members of their ethno-racial ingroup. This too may be conducive to BMGM's positioning as ingroup 'black sheep'. However, there is no existing empirical research which 
examines the social (interpersonal and intergroup) dynamics of BMGM in GASC specifically within the British context. This constitutes an important lacuna in the literature given that 'race' may be less of an issue than religion, in light of the recent surge in Islamophobia, which emphasises the alleged incompatibility of Islam and 'Western tolerance' (Jaspal \& Cinnirella, 2010c; Richardson, 2004). Fundamentally, while Minwalla et al.'s (2005) study explores how Muslim gay men may feel as a result of sharing gay space with White gay men (WGM), the present study explores social representations of interpersonal relations with WGM held by BMGM.

The study of interpersonal relations must be contextualised. Muslim can face a multitude of cultural constraints, including 'honour', close familial and kin relationships and the theologically based requirement that all Muslims should be married. This renders the quasi-public expression of sexuality associated with frequenting GASC a potential threat for belonging within the extended family (e.g. Whitaker, 2006; Yip, 2004). Moreover, it has been found that some Muslim gay men may avoid disclosing their sexual identity due to the perceived possibility of violent retaliation from religious ingroup members (Minwalla et al., 2005). Indeed, violence as a punishment for homosexuals has been endorsed by some sections of the Muslim community in Britain (Siraj, 2009). Clearly, this is likely to have negative implications for general psychological well-being.

\section{Aims of the study}

The present paper has two principle aims; one is substantive and the other is theoretical. The substantive interest lies in the phenomenological experiences of BMGM in GASC. Given the lack of clarity regarding the socio-psychological consequences of frequenting gay space, the present study seeks to explore these issues through the first-hand accounts of BMGM themselves. More specific questions include: (i) the impact of frequenting GASC for the principled operation of identity processes; (ii) how participants perceive and construe the social networking opportunities afforded to them in GASC; and (iii) the perceived nature of interpersonal relations with Muslim and non-Muslim gay men, as well as members of the superordinate 'Asian' ingroup.

The theoretical aims of this paper are: (i) to demonstrate the heuristic value of IPT in research on conflictual identities; (ii) to explore how interpersonal relations may impact intrapsychic processes; and (iii) to further elucidate the relationships between the identity principles, which remains a largely unresolved issue in IPT research.

\section{METHOD \\ Participants}

A sample of twenty self-identified BMGM was recruited from the Pakistani community in a city in the East Midlands of England. Although all participants claimed to be gay, it is acknowledged that the category 'gay' may have distinct meanings for individuals; some may conceptualise gay identity in terms of behaviour, while others may perceive this in terms of an immutable self-aspect (Jaspal \& Cinnirella, 2010a). The study focused solely upon the experiences of British-born selfidentified Muslims of Pakistani heritage in order to recruit a more homogeneous sample, which was deemed important due to the small sample size. Participants were male with a mean age of 26.3 years (SD: 2.6). Four participants were university students, ten were college students, and the remaining six had GCSE/A-levels (equivalent to high school diploma in the USA). A snowball sampling strategy was employed.

\section{Procedure and data generation}

The interviews were guided by a semi-structured interview schedule consisting of eight exploratory, open-ended questions. The schedule began with questions regarding self-description and identity, followed by more specific questions on experiences of frequenting GASC; relations 
with other gay men; feelings and emotions evoked when thinking about interpersonal relations with other gay men.

Interviews lasted between 60 and 120 minutes. They were digitally recorded by the interviewer and transcribed verbatim by the first author.

\section{Analytic approach}

The data were analysed using qualitative thematic analysis, which has been described as 'a method for identifying, analysing and reporting patterns (themes) within data' (Braun \& Clarke, 2006, p. 78). This approach was considered particularly useful since it allows the researcher to engage with theory in a quasi-deductive fashion in order to add theoretical depth to the data analysis (see Boyatzis, 1998; Hayes, 1997 for more on deductive approaches to qualitative research). Moreover, 'theoretical' thematic analysis allows for the generation of new theory and provides opportunities for developing models. Given the present study's aim to advance and to develop identity process theory, use of this particular method was considered highly advantageous. The study also aimed to capture participants' attempts to make sense of their personal and social worlds, with a particular focus on identity and interpersonal relations. It is noteworthy that this study does not aim to make generalisable statements regarding BMGM due to the small sample size but rather aims to identify key issues and to develop hypotheses which may be tested in research with larger sample sizes.

Given our research aim to explore participants' subjective experiences and the meanings attached to these experiences, this study adopts a realist epistemological approach to participants' accounts. Thus, it views participants' talk as a fairly reliable reflection of their cognitions. The realist epistemological approach within thematic analysis allows the data analyst to theorise motivations, subjective experience, and meaning. This is important partly because this study endeavours to enhance one's understanding of the motivational principles of identity when identity is subjectively perceived to be threatened. Thematic analysis allows for this level of analysis primarily because a largely unidirectional relationship is assumed to exist between language and cognition (Braun \& Clarke, 2006).

\section{Analytic procedures}

The recordings were transcribed by the first author, who also read the transcripts repeatedly in order to become as intimate as possible with the accounts. During each reading of the transcripts preliminary impressions and interpretations were noted in the left margin. These initial codes included inter alia participants' meaning-making, particular forms of language, and apparent contradictions and patterns within the data. Subsequently, the right margin was used to collate these initial codes into potential themes, which captured the essential qualities of the accounts. As highlighted by Braun and Clarke (2006, p. 82), 'a theme captures something important about the data in relation to the research question, and represents some level of patterned response or meaning within the data set.' Thus, the 'keyness' of the themes reported in the present study depended upon their importance in relation to the research questions. The themes were reviewed rigorously against the data in order to ensure their compatibility and numerous interview extracts were listed against each corresponding theme. It was at this stage that specific interview extracts, which were considered vivid, compelling and representative of the themes, were selected for presentation in the final research report. Finally, superordinate themes representing the themes derived from the twenty accounts were developed and ordered into a logical and coherent narrative structure.

In the quotations from participants which are presented in the next section, three dots within square brackets indicate where material has been excised; other material within square brackets is clarificatory; text in italics are highlighted by the authors to illustrate their centrality in the discussion. Participants' real names have been replaced with pseudonyms. 


\begin{abstract}
ANALYSIS
This section reports some of the most important themes regarding participants' accounts of gay identity and interpersonal relations with other gay men. These include: (i) "self continuity and the transition from straight to gay space"; (ii) "interpersonal relations with other gay men and self/other-categorisation"; and (iii) the role of "interpersonal contact/ identification with WGM as an identity enhancer".
\end{abstract}

\title{
Self continuity and the transition from straight to gay space
}

Many participants reported having frequented gay space (Hughes, 2003), which they described as 'going out on the [gay] scene'. At the intrapsychic level, the experience of entering gay space seemed to induce psychological upheaval due to fundamental changes in self-perception:

"If I'm honest with you, the first time I went out on the [gay] scene my life just changed. It was all upside down. I didn't know what I was doing, where I was anymore, I mean, I wasn't all there when my mum or dad were speaking to me. It was all too much for me because it felt like I was already taking that step into the gay world and that was just making me think "what kind of a Muslim am I?’” (Haroon)

"It was a big shock afterwards, the change from being not totally gay to being gay because I'd like acted on it, it was stressing me out” (Faisal)

Entry in gay space seemed to embody a sexual 'coming of age', since it provided psychosocial evidence of one's sexual identity. Given that the former 'self' prior to entry in gay space was constructed as being 'not totally gay' it could be argued that the denial strategy sheltered the identity structure from the potential threats associated with being 'totally gay'. Threats to the continuity principle can result from 'taking that step' from a primarily heterosexual social space (i.e. a Muslim home) into 'the gay world'. Crucially, it is not the notion of change itself which is threatening for identity, since it is possible to maintain self-perceived 'continuity across time and situation' even in contexts of social or psychological change, for instance (Breakwell, 1986, p. 24). Indeed, Breakwell (1988, p. 194) has noted that 'there can be continuity in inconsistency'. Rather, it is the disruptive nature of the change which renders it threatening for identity: 'it [my life] was all upside down'.

Moreover, Haroon alludes to feelings of 'depersonalisation'; he reflects upon the experience of having lost transiently aspects of his personal identity and feeling momentarily estranged from himself (Rosenberg, 1984; see also Breakwell, 1986). Similarly, Faisal conceptualised his feelings following his first experience 'on the scene' in terms of stress possibly because the change required in his identity structure in order to accommodate the new 'self' was unanticipated and disruptive: 'it was a big shock'. Thus, the threat to continuity ensues from the perception of those forms of change, which induce disruption in the identity structure:

"It does make me think I've started to drift from God and Islam by doing this [frequenting gay space]” (Salim)

Here, Salim's sense of continuity is jeopardised by his perceived self-distancing from God and Islam as a result of frequenting gay space. Haroon's self-reported feelings of depersonalisation could be attributed to his continual inability to accommodate within the identity structure the transition from his sheltered domestic environment into 'the gay world'. Interpersonal contact with his parents subsequent to his experience of gay space renders salient the memory of his former ('not totally gay') 'self', inducing feelings of guilt. Evidently, the juxtaposition of a former 
'self' and a new 'self', due to individuals' inability to resort to strategies of compartmentalism (cf. Yip, 2004), can threaten temporal continuity.

It would be inaccurate to regard participants' incipient experiences in gay space solely in terms of their implications for the continuity principle of identity. Haroon's above-cited account additionally alludes to the concurrent threat to psychological coherence given that his selfpositioning within gay space, a behaviour associated with sexual identity, is said to problematise his religious identity as a Muslim (Jaspal \& Cinnirella, 2010a). This clearly demonstrates that his gay and Muslim identities are perceived as being inter-connected in that they have direct repercussions for one another within the identity structure. The perceived incompatibility arises from his perception that occupancy of gay space challenges the authenticity of his Muslim identity: 'what kind of a Muslim am I?' Jaspal and Cinnirella (2010a) have discussed some of the ways in which BMGM might attempt to cope with the perceived incompatibility of being Muslim and gay. Here it is sufficient to note that the intrapsychic consequences of this identity configuration, which became salient for some participants upon entry in gay space, were generally negative. More specifically, this was conducive to identity threat. An additional concern in the present paper lies in the potential repercussions of experiencing gay space for interpersonal, and especially interethnic, relations. This is discussed in the following section.

\section{Interpersonal relations with other gay men and self-/ other-categorisation}

Towards a common ingroup identity: British Asian gay men

Although most participants' accounts invoked the psychological distress which had followed their early experiences in gay space, there was general consensus among participants that the advent of various 'gay nights' organised specifically for the South Asian gay community (of which Pakistani Muslims form part) enhanced interpersonal relations:

"I do go out on the scene now and then mainly because there's a couple of nights where I can go out with my Asian mates and I know I'll meet Asian lads when I'm out. Like at Saathi [a monthly nightclub event for South Asian gay men] I know most of the guys really and there's always new ones who come out.” (Saqib)

For some participants, 'gay nights' like Saathi constituted an opportunity to establish interpersonal relations with other British Asian gay men (BAGM), both Muslim and non-Muslim. Participants' general preference for socialising with gay men from within their own ethnic group was attributed to the widespread social representation that other BAGM would, as a result of their similar ethnocultural backgrounds, understand some of the constraints they face:

Saqib: "I do prefer making gay friends who are Asian because they're much more understanding than White lads."

Interview: "In what sense?"

Saqib: "Well, you know, they'll understand we need to hide stuff from our parents and like we lie to get out at night and stuff like that. Plus, they know what the score is, we get married eventually and there's no long-term relationships. White guys get all sentimental."

Interviewer: "Is sentimental a bad thing?"

Saqib: “[...] It ends up just taking the power from you, you can’t just say 'stop' and it ends when there's suspiciousness. It's the other guy that's in the driver's seat."

As Saqib is probed for further information regarding the reasons underlying his preference for BAGM, it becomes apparent that this preference constitutes a strategy of enhancing identity. Saqib's account alludes to a desirable 'future self', which consists of the stated intention to enter a heterosexual marriage: ‘we get married eventually’ (see also Jaspal \& Cinnirella, 2010a). This 
exemplifies an a priori strategy of defending a sense of continuity with the 'self' prior to frequenting gay space.

A relationship with a WGM could potentially threaten the self-efficacy principle of identity, since this may result in a loss of 'power'. The sense of power invoked by Saqib refers to flexibility in the relationship, namely the ability to end it at potentially risky points, i.e. in order to avoid involuntary disclosure of his sexuality. Saqib perceives WGM as lacking access to those cultural representations which he views as being consensually shared by BAGM, namely that it is normative, and even necessary, to conceal one's sexuality from the public eye (Murray, 1997). The perceived inability to preserve the powerful position, which would be afforded to him in a relationship with a BAGM, could potentially jeopardise the human need for 'competence and control' over one's affairs and social environment, namely self-efficacy (Breakwell, 1993, p. 205). Although self-efficacy is not threatened in real terms (Saqib elucidated the reasons underlying his decision not to engage in relations with WGM), it seems that a potential threat to the principle is envisaged. Thus, it is likely that his preference for BAGM at least partly constitutes a strategy of enhancing the self-efficacy principle of identity, that is, it is actively sheltered from potential future threats.

Although Jaspal and Cinnirella (2010a) argue that self-efficacy may be less associated with gay identity among Muslims than psychological coherence and continuity, here it seems that by preserving and enhancing self-efficacy, participants may thereby seek to enhance other subjectively more important principles underlying their identities. The competence and control which individuals attempt to retain are pivotal in ensuring that their sexual identities are not disclosed to significant others (i.e. parents, relatives and friends). Crucially, it seems that disclosure to these ingroup members could seriously compromise identity:

Salim: "You've got to hope nobody guesses [that you are gay]. Life is not too hard until someone finds out and blabs"

Interviewer: "But why?"

Salim: "You get treated like a piece of shit then. Like you're not a man or a woman, just a 'khusra' [hermaphrodite]” (Salim)

Some participants reproduced the social representation that WGM are more committed to their gay identities and that they, therefore, expect BAGM to disclose their sexual identities to significant others. This perceived pressure to disclose one's sexuality is viewed by some individuals as jeopardising feelings of competence and control over their identities, resulting in potential threats to self-efficacy (Breakwell, 1986). This loss of self-efficacy, which is coterminous with forced disclosure, may in turn be conducive to a loss of self-esteem. This is manifested unambiguously in Salim's extract; his fear of disclosure arises from his perception that BAGM would 'get treated like a piece of shit'. It is anticipated that individuals would not only cease to be valued by ingroup members, but they would suffer dehumanisation (Haslam, 2006). More specifically, Salim's account alludes to a 'feared self' ascribed by ingroup members, with hermaphroditic characteristics: 'you're not a man or a woman, just a 'khusra' [hermaphrodite]' (see Markus \& Nurius, 1986). These anticipated responses from ingroup members would almost certainly result in threats to self-esteem, that is, the 'motivation to maintain and enhance a positive conception of oneself' (Gecas, 1982, p. 20). Consequently, Salim is required to preserve his self-efficacy in order to establish a protective boundary around the self-esteem principle of identity (Breakwell, 1986). Given the emphasis upon self-esteem in participants' accounts, manifested by the fear of devaluation and dehumanisation by ethno-religious ingroup members, this principle is subjectively prioritised, although it can be protected only by preserving self-efficacy. 
Since relationships with WGM are perceived as leading to involuntary disclosure and thus identity threat, it is quite possible that some BMGM, in their attempts to actively preserve and enhance the principles, may evade interpersonal relations with WGM.

\section{Social representations of the White gay 'Other'}

Given the fear of disclosure, it was deemed necessary by some BMGM to establish links with gay men in a similar socio-cultural situation who would therefore share their social representations regarding the strict socio-cultural norms governing their sexual identities. To return to Saqib’s above-cited account, it is reasonable to conclude that he perceives WGM as 'other' to himself. He reproduced what appeared to constitute a pervasive representation among participants that WGM generally lack an understanding of BMGM's socio-cultural constraints. Indeed, this representation was reproduced even by those participants who did not reject the possibility of a future relationship with a WGM:

“Don't get me wrong, I do like White guys but you know they'll never understand you and your parents and that" (Kamran)

In Mo's account, the ethno-racial category Asian is employed to categorise the 'understanding ingroup', while the racial category 'White' denotes the outgroup. More specifically, 'White guys get all sentimental' while '[South Asian gay men] know what the score is'. This pattern of self/other categorisation among our British Muslim gay participants deviates from pervasive empirical and theoretical findings that, in general, second generation British South Asians prefer self-/other categorisation in terms of more specific ethno-religious identity categories (e.g. 'British Indian', 'British Muslim' rather than 'British Asian') (Ballard, 1990; Jaspal \& Cinnirella, 2010b; Raj, 2000;). Nonetheless, here almost all participants preferred the superordinate identity category Asian, which seemed to indicate a sense of solidarity and 'one-ness' among BAGM:

Interviewer: "What kind of guy would you ideally go for, like in terms of origins, ethnic origins?" Iqbal: "Asian. I only go for Asian guys really.”

Although Jaspal and Cinnirella (2010a) found that gay identity was not sufficiently salient, psychologically, to over-ride Muslim identity and to provide a sense of 'one-ness' on the basis of a common gay identity, here it seems that religious identity (Muslim) may become relatively latent vis-à-vis ethno-racial identity (Asian). In other research contexts, self-categorisation in terms of more specific ethno-national and/ or ethno-religious identities have been hypothesised to enhance the (group) distinctiveness principle of identity, given that group members can perceive, at the intrapsychic level, and demonstrate interpersonally the uniqueness of their ingroup vis-à-vis potentially similar groups with which the ingroup may be said to overlap (Jaspal \& Cinnirella, 2010b; Jaspal \& Coyle, 2010a). However, in this case the distinctiveness principle may be sacrificed in order to enhance the belonging principle in a social context in which several participants already perceived themselves to be 'other' to WGM:

"You see, Pakistani guys and Indian guys are the ones that will accept you when you say you can't stay out or go to that club because your uncle is a taxi-driver or something. Gore [White people] ain’t going to understand it. They just say the culture is backward” (Tahir)

The belonging principle of identity, which 'refers to the need to maintain or enhance feelings of closeness to, and acceptance by, other people,' faces threats from WGM in gay space (Vignoles et al., 2006, p. 310). The perceived lack of acceptance by WGM is associated with the social representation that they derogate BMGM's cultural background rather than understanding the 
constraints associated with it. Conversely, it is both Indian and Pakistani gay men who fulfil the need for closeness to, and acceptance by, relevant others, since they are viewed as exhibiting an understanding of these cultural constraints. It is likely that the belonging principle of identity is acutely important for identity processes in gay space given that many BMGM use this social space with the primary aim to acquire feelings of closeness and acceptance from understanding others:

"I guess I did it [went out on the scene] to know people and to see that I'm not the only one on the planet [who is gay]” (Kamran)

This may explain why competing principles, such as group distinctiveness, may be sacrificed in order to enhance belonging.

Although the belonging principle is most clearly benefited from close relations with other BAGM, the analysis revealed the potential benefits for other identity principles, which rendered relations with BAGM particularly advantageous in identity terms. This is understandable given that gay men of both Pakistani and Indian descent face similar dilemmas in reconciling their ethnic and sexual identities and could thus be said to share a similar 'life narrative' vis-à-vis these identities (Bhugra, 1997). As discussed earlier, this sense of common experience could be viewed as giving rise to a common ingroup identity, which over-rides religious differences between group members (Gaertner \& Dovidio, 2000). The superordinate ethnic category Asian encompasses a range of national, religious, ethnic and linguistic subgroups (see Ballard, 1994). Members of the superordinate category Asian were, nonetheless, said to share similar social representations of being gay and 'Asian' and the psychosocial complications this may entail. Conversely, for some BMGM, identification and interpersonal contact with WGM could have contradictory outcomes for identity, as discussed in the next section.

\section{Interpersonal contact/ identification with WGM as an identity enhancer}

It has been argued that participants generally eschewed relations with WGM due to the social representation that WGM are 'excessively' open about their sexuality. This could be problematic because 'coming out' was not perceived as a viable option by many participants. Crucially, individuals may still define themselves as 'gay', even if they do not disclose their sexuality to others (Jaspal \& Siraj, in press). However, there were some dissenting voices regarding the value of interpersonal relations with WGM. For instance, Kasim strategically reproduced dominant representations of White Britons as tolerant, accepting and 'open' about sexuality (see Jaspal \& Cinnirella, 2010a). It is noteworthy that this representation was employed to highlight a positive quality of WGM. While some participants perceived this 'openness' in negative terms as a potential threat to their identities, Kasim re-construed the representations in positive terms and utilised them strategically as a positive source of inspiration (Breakwell, 2001). This social representation enabled him to attribute positive meaning and significance to his 'coming out' experience:

Kasim: "I couldn't stand the sight of my parents and was sick of my culture, my religion, the lot. I just hung out with my [White] mates who were all out in the open. They helped a hell of a lot. I wouldn't have even admitted it to myself let alone my folks if my mates hadn’t been there.”

Interviewer: "Why's that?"

Kasim: "They [White friends] showed me that there's nothing wrong with being gay. If they can do it, why can't we? [...] I've never been so happy in my life.”

Kasim's awareness and acceptance of the social representation that White Britons are generally accepting towards homosexuality empowers him to seek a sense of belonging beyond the confines of his ethno-religious ingroup. Given that other participants viewed the prospect of 'coming out' 
as impossible, it could plausibly be argued that for Kasim social representations of British openness enable him to accomplish a task pervasively regarded as impossible (Jaspal \& Siraj, in press). Accordingly, it is inferred that this enhances the self-efficacy principle of identity (Breakwell, 1992).

Kasim's strategic self-positioning alongside WGM may enhance the meaning principle as it allows him to find significance and purpose in his identity as a gay man. Crucially, he is able to attribute positive meanings to his gay identity, which enables the meaning principle to function productively in accordance with the evaluation process of identity (Breakwell, 1986). The meaning principle constitutes a key predictor of psychological well-being (McGregor \& Little, 1998), given that it plays a fundamental role in coping with major life events (e.g. Golsworthy \& Coyle, 1999). Even a cursory glance at the literature on BMGM reveals the appropriateness of conceptualising 'coming out' experiences in terms of potentially traumatic life events (Jaspal \& Cinnirella, 2010a; Jaspal \& Siraj, in press).

Pivotally, Kasim's interpersonal relations with WGM allow him access to a repertoire of positive meanings, which can now be attributed to gay identity. This elucidates the positive outcomes of self-positioning alongside WGM for the self-esteem principle of identity. This is reflected in his statement that 'I've never been so happy in my life'. While it is acknowledged that self-esteem and the six other principles should be viewed as unique and independent principles (Vignoles, Chryssochoou \& Breakwell, 2002), the present data suggest that the positive enhancement of the meaning principle (i.e. by allowing individuals access to a repertoire of positive meanings attributable to gay identity) will likely result in greater self-esteem.

It has been observed that individuals will self-categorise in specific ways in order to enhance the principled operation of identity processes (Jaspal \& Cinnirella, 2010b). This identityenhancing strategy was observable in the present study given that participants did not consistently identify with WGM or with the national category British. Conversely, in contexts evoking personal threats from ingroup members (e.g. punishment, disownment, forced marriage) identification with an alternative category available to them (e.g. British) became much more pervasive:

Interviewer: "And what would you do [if your parents force you to marry]?”

Ali: "I'm British, not Pakistani, and this is England, not Pakistan, so that ain't going to happen, full stop [...] Yeah, I'll still go on holiday to Pakistan and if they try anything, I know my rights. I know where the British embassy is.”

On one level, the prospect of forced marriage leads Ali to invoke his membership in the national category British. This perhaps enables him to maintain his personal sense of continuity (as an unmarried gay man), and to repudiate his parents' coercion that he should be married in Pakistan. Self-categorisation as British positions him outside of the 'jurisdiction' of Pakistani and/ or Muslim norms and values, thereby enabling him to repudiate the social and behavioural 'criteria' against which he and his behaviour are evaluated. It is likely that self-categorisation as British critically safeguards the self-efficacy principle, given that his rejection of the aforementioned social criteria allow him to preserve his sense of independence and personal control over his life and future (Breakwell, 1992). Forced marriage constitutes, by definition, a threat to one's selfefficacy given that through marital coercion one loses choice, competence and control.

British national identity endows Ali with feelings of self-efficacy since even in Pakistan he perceives himself to be in a legal position to repudiate the norms and values perceived to be associated with Pakistani culture by seeking the assistance of the British embassy. Crucially, it is by virtue of this instrumental attachment to British national identity that he perceives these feelings of self-efficacy (Kelman, 1997). 
“To be fair, yeah, I didn’t even know White guys before I started going out [on the scene] so how was I going to feel British? When I met guys on the scene I realised what I can do with my life here and what I couldn’t ever dream of doing away from Britain” (Faisal)

The data suggested that some participants discovered the potential instrumental (i.e. practical, material) benefits associated with being British and with living in Britain as they began to frequent GASC. Previous research reveals the prevalence of the instrumental form of national attachment among British South Asians (Jacobson, 1997; Vadher \& Barrett, 2009). Here, this form of national attachment is exploited in order to serve a particular identity function, namely the accommodation of gay identity in the self-concept. Furthermore, it is employed to enhance the meaning and selfefficacy principles of identity: 'I realised what I can do with my life here'.

In some cases, this strategic identification with Britishness entailed the negative construal of the social representations associated with their ethno-religious culture:

“They're [Muslims] on another planet. We don't do this violent nonsense. We've moved on since the $6^{\text {th }}$ century and we don't stone gay people any more. In this country we've all got our rights" (Kasim)

The relationship between national identity and sexual identity is a complex one. Jaspal and Cinnirella (2010a) have found that in order to cope with the intrapsychic threats associated with the perceived incompatibility of self-identifying as gay and Muslim led some participants to attribute their gay identities to their early socialisation within 'British culture', which was said to be morally deficient. In short, this national culture was perceived as encouraging gay identity. Although the present example is qualitatively contradictory, since Britishness is construed in positive terms, the fundamental psychological process remains the same. Individuals selfcategorise strategically in order to enhance the principled operation of identity processes (Breakwell, 1986).

\section{DISCUSSION}

Almost all of the current empirical research on Muslim gay men highlights the potential for identity conflict, which, from an IPT perspective, may be regarded in terms of identity threat (Jaspal, 2010; Jaspal \& Cinnirella, 2010a; Jaspal \& Siraj, in press). The present paper contributes to this literature by predicting and explaining some of the specific causes of identity threat and the implications for interpersonal relations among a small sample of BMGM of Pakistani descent. While these data are by no means generalisable, they are useful in developing hypotheses, which may be tested multi-methodologically with larger samples of BMGM of other ethnic backgrounds. For instance, it is argued that for many participants it is difficult to maintain a sense of continuity between two temporal 'selves', namely that the 'self' prior to entry in gay space and the 'self' subsequent to this experience. The psychological implications of participants' transition into gay space are likely to be considerable given their consequential exposure to gay affirmative social representations, which construct homosexuality in terms of an acceptable addition to the identity structure. This incoming information, though conducive to the assimilation of gay identity, is likely to cause disruption in the identity structure, since the accommodation of this identity may be obstructed by existing social representations derived from religious identity (Jaspal \& Cinnirella, 2010a). Diachronically, this poses threats to the continuity principle but, synchronically, this is likely to have negative consequences for the psychological coherence principle given the problematic reconciliation of the distinct social representations associated with ethno-religious contexts and GASC. The present paper argues that social and psychological entry in GASC may be conducive to threats at the intrapsychic level of cognitive processing among some BMGM. 
Moreover, the more general implications of 'going out on the scene' for psychological well-being may, in part, be negative. Participants described feelings of depersonalisation as a result of their inability to maintain a sense of temporal continuity and synchronic compatibility between the two 'selves'. Furthermore, an acute sense of guilt was observable in several participants' accounts due to their internalisation and, at least partial, acceptance of the social representation that homosexuality is not a defining feature of Muslims (Siraj, 2009). On the other hand, entry in gay space offered scope for the re-construal and re-evaluation of gay identity and its position within the identity structure in relation to the other components of identity. This intrapsychic strategy of coping was facilitated and actively encouraged by experiences in GASC (Breakwell, 1986). The properties of this social position came to be evaluated by some participants in unambiguously positive terms, given the salience of social representations of gayness as a 'normal' component of identity in gay affirmative social contexts. Moreover, for the first time, being gay was perceived as constituting a positive shared self-aspect underlying a collective identity. The re-construal of existing representations of homosexuality in a positive light could threaten continuity, given that BMGM are essentially required to abandon previous modes of thinking associated with their generally salient religious identity. In order for reconstrual to take place with minimal threats to identity, individuals probably need to revise the salience of identity principles, so that continuity is transiently rendered latent vis-à-vis self-esteem. This is enhanced by the acceptance and internalisation of gay affirmative social representations (Breakwell, 1986, 2001).

The study of participants' experiences of GASC has allowed insight into interpersonal and intergroup relations between BMGM and non-Muslim gay men. Although intergroup relations has been afforded cursory attention in the literature (e.g. Minwalla et al., 2005), there is no previous research exploring the ethno-religious dynamics of GASC within the British context. The present results suggest that some BMGM may exhibit reservation at the prospect of close interpersonal contact with WGM, as this may be perceived as leading to involuntary disclosure of one's sexuality. Involuntary disclosure was, in turn, perceived in threatening terms. From an interpersonal perspective, disclosure to significant others could allegedly result in physical violence or even death due primarily to the importance of izzat (honour) in South Asian cultures (Jaspal \& Siraj, in press). Furthermore, disclosure may have be particularly associated with the belonging and self-esteem principles of identity, since BMGM may perceive disclosure as coterminous with ostracisation from the ethno-religious ingroup and as conducive to ridicule and derogation from ethno-religious ingroup members, threatening these principles. This exhibits the complexity of group dynamics in GASC; accounts of group dynamics based on notions of 'race' and prejudice are unlikely to offer an adequate explanation here (cf. Minwalla et al., 2005; Nasir, 2006; Riggs, 2006). While the present paper acknowledges this dimension of the BMGM experience, it adds the caveat that, in many cases, processes of exclusion and 'otherisation' may be reciprocal and dual-dimensional, in that BMGM may themselves actively eschew interpersonal relations with WGM. This contention is supported by the social representation of the White gay 'Other', observable in the data presented in this paper.

However, in some ways, close interpersonal relations with WGM may, conversely, enhance the principled operation of identity processes. As discussed, contact with WGM in gay space allows BMGM exposure to gay affirmative social representations, which enable individuals to attach positive meanings to gay identity. Moreover, the re-construal of gay identity as 'normal' is likely to encourage BMGM to perceive significance and purpose in their existence within the social matrix (Baumeister, 1991). In short, this will allow individuals to view gay identity as a positive and meaningful component of the self-concept. Crucially, this strategy is likely to be beneficial only for those BMGM who have already begun to reconcile gay and Muslim identities at the intrapsychic level, rather than those who consistently regard these identities as wholly incompatible. There was a tendency for some BMGM to stress their identification with WGM 
when the self-efficacy principle of identity was perceived to face potential future threats (e.g. by imagining their parents' coercions of marriage). Self-alignment alongside WGM, who are beyond the authoritative 'reach' of participants' parents, perhaps strengthened their sense of self-efficacy, since they became resistant to external coercion of this kind. Strategic identification in this way has been identified as a strategy for enhancing identity processes (Jaspal \& Cinnirella, 2010b).

Identification and/ or solidarity with WGM may have contradictory consequences for identity since one principle (i.e. meaning) may be enhanced while others may face threats (i.e. selfesteem/ belonging as a result of feared disclosure, for instance). Close attention to participants' accounts reveals that the extent to which interpersonal relations with WGM is positively construed is likely to be associated with principle salience, that is, which principle is psychologically salient at any given point (Breakwell, 1986). For instance, for participants who contemplated selfdisclosure the meaning principle seemed to acquire salience (see Kasim's account), while the belonging principle was rendered relatively latent. A key argument of the present paper is that individuals strive to enhance those identity principles which are perceived to be conducive to positive identity construction. The notion of principle salience allows for the transient activation of subjectively important principles and the de-activation of less important principles. Group dynamics will likely be organised in ways which enhance those identity principles, which are salient at any given time (Jaspal \& Cinnirella, 2009).

Since, for some BMGM, solidarity with WGM may be eschewed in order to enhance belonging within the ethno-religious group, belonging within gay affirmative social contexts may, conversely, be exposed to potential threat. However, this potential threat is actively alleviated, and belonging is thereby enhanced, through the expression of solidarity and 'one-ness' with other British Asian gay men (BAGM). This echoes the common ingroup identity model (Gaertner \& Dovidio, 2000), which proposes that ingroup and outgroup categorisation (i.e. Pakistani Muslim versus Indian Hindu) may be shifted to a superordinate level (i.e. Asian), which encourages members of the two groups to view themselves as belonging to a common, more inclusive ingroup. There is no evidence to suggest that non-Muslim BAGM would lay claim to this common ingroup identity; in fact, there is a fair amount of empirical and theoretical work suggesting that more specific ethnic and religious identities are generally preferred by many British South Asians (e.g. Raj, 2000; Jaspal \& Cinnirella, 2010b). This reiterates a key argument in this paper, namely that patterns of categorisation and identification, which favour identity processes, will be exploited by individuals.

On a more general theoretical level, the present paper suggests that particular principles may be relatively more or less associated with specific identities. It has, for instance, been found that the self-efficacy principle seems be less important than continuity and psychological coherence for BMGM who are not openly gay (Jaspal \& Cinnirella, 2010a). Thus, there may be a hierarchy of identity principles associated with specific identities predicting principle salience. The present data suggest that self-esteem and belonging are likely to feature prominently in this hierarchy of principles. Furthermore, it is suggested that individuals may attempt to enhance the prioritised principles through the concurrent enhancement of other principles. For instance, participants' enhancement of self-efficacy was said to be aimed at protecting self-esteem. This elucidates the active agency of individuals in enhancing identity; human beings likely possess the heuristic skills required to detect relationships between identity principles.

It is noteworthy that the present paper makes a distinction between 'coping strategies' and 'enhancing strategies' (see also Vignoles, Chryssochoou \& Breakwell, 2000). While coping strategies are defined as 'any activity, in thought or deed, which has as its goal the removal or modification of a threat to identity' (Breakwell, 1986, p. 78), enhancing strategies refer to active attempts on the part of individuals to enhance the principled operation of identity processes even in the absence of subjectively perceived threat. Such strategies may be implemented by individuals when they perceive scope for the enhancement of identity principles, or in situations in which 
identity threat is pre-empted by the individual. For instance, isolation can only be said to constitute a 'coping strategy' in the event of subjectively perceived threat (Breakwell, 1986). This conceptual distinction demonstrates that IPT is more than just a 'reactive model' (cf. Bosma, 1995, p. 13).

In terms of the practical value of these findings, some suggestions are offered. This paper contributes to a broader campaign in the social sciences to encourage greater understanding of the potential socio-psychological obstacles associated with being gay and of religious faith (Coyle \& Rafalin, 2000; Yip, 2005). More specifically, it is hoped that this paper elucidates the particular complexity of BMGM's position within GASC given the diverse implications for identity processes. This paper aims to dispel any potential naiveté regarding this complexity. While the integration of BMGM in GASC is likely to benefit some dimensions of identity, it also entails potentially threatening consequences for other dimensions. Social change which benefits the interpersonal level of human interdependence may simultaneously entail negative repercussions at the intrapsychic level. Indeed the integrative nature of IPT allows for predictions regarding the inter-relations between these multiple dimensions. It is hoped that future research in this area will make use of IPT's integrative approach, respecting the multi-faceted nature of the BMGM experience.

\section{Conclusion}

This study applies IPT to accounts of gay identity and interpersonal relations from a group of BMGM. It is suggested that a conceptual distinction between diachronic and synchronic consequences of distinct coping strategies would reveal their broader implications for identity principles and hence their overall efficacy. Moreover, the efficacy of a given coping strategy may be enhanced through combination with others, despite their functioning at a distinct level of human interdependence, for instance. Finally, a distinction between (reactive) coping strategies and (active) enhancing strategies is proposed.

It is contended that the most effective method of enhancing well-being among BMGM, and possibly other ethnic minority gay men, is to seek to modify (i) existing social representations of homosexuality within ethno-religious contexts, and (ii) existing representations of BMGM and other ethnic minorities in gay space. This dual process of social change may eventually render active participation in GASC, interpersonal contact with other gay men and disclosure of one's sexuality to significant others less threatening for identity processes among BMGM. In fact, these three socio-psychological strategies of mobility are likely to have markedly positive consequences for psychological well-being among this group.

\section{REFERENCE}

Abraham, I. (2009). 'Out to Get Us': Queer Muslims and the clash of sexual civilization in Australia. Contemporary Islam,3(1),79-97.

Abraham, I. (2010). 'Everywhere you turn you have to jump into another closet': Hegemony, hybridity, and Queer Australian Muslims. In S. Habib (Ed.), Islam and Homosexuality, Vols 1 and 2, (pp.395-412). Santa Barbara, CA: Praeger.

Balka, C. \& Rose, A. (1989). Twice blessed: on being lesbian or gay and Jewish. Boston, MA: Beacon Press.

Ballard, R. (1990). Migration and kinship: the differential effect of marriage rules on the processes of Punjabi migration to Britain. In C. Clarke, C. Peach \& S. Vertovec (Eds.), South Asians overseas: contexts and communities (pp. 219-249). Cambridge: Cambridge University Press. 
Ballard, R. (1994). Desh pardesh: the South Asian experience in Britain. London: C. Hurst.

Baumeister, R. F. (1991). Meanings of life. New York: Guilford.

Bhugra, D. (1997). Coming out by South Asian gay men in the United Kingdom. Archives of Sexual Behaviour, 26(5), 547-557.

Boellstorff, T. (2005). Between religion and desire: being Muslim and gay in Indonesia. American Anthropologist, 107(4), 575-585.

Bosma, H. A. (1995). Identity and identity processes: what are we talking about? In A. Oosterwegel \& R. A. Wicklund (Eds.), The self in European and North American culture: development and processes (pp. 5-17). Dordrecht, Netherlands: Kluwer.

Bouhdiba, A. (1998). Sexuality in Islam. London: Saqi Books.

Boyatzis, R. E. (1998). Transforming qualitative information: Thematic analysis and code development. London: Sage.

Braun, V. \& Clarke, V. (2006). Using thematic analysis in psychology. Qualitative Research in Psychology, 3, 77-101.

Breakwell, G.M. (1986). Coping with threatened identities. London: Methuen.

Breakwell, G.M. (1988). Strategies adopted when identity is threatened. Revue International de Psychologie Sociale, 1, 189-203.

Breakwell, G. M. (1992). Processes of self-evaluation: efficacy and estrangement. In G.M. Breakwell (Ed.), Social psychology of identity and the self-concept (pp. 335-355). Surrey: Surrey University Press.

Breakwell, G. M. (1993). Social representations and social identity. Papers on Social Representations, 2, 198-217.

Breakwell, G.M. (2001). Social representational constraints upon identity processes. In K. Deaux \& G. Philogene (Eds.), Representions of the social: bridging theoretical traditions (pp.271-284). Oxford: Blackwell.

Coyle, A. (1991). The construction of gay identity. Unpublished doctoral dissertation, University of Surrey, Guildford, UK.

Coyle, A. \& Rafalin, D. (2000). Jewish gay men's accounts of negotiating cultural, religious and sexual identity: a qualitative study. Journal of Psychology and Human Sexuality, 12, 21-48.

Eliason, M.J. (1996). Identity formation for lesbian, bisexual, and gay persons: beyond a "minoritizing" view. Journal of Homosexuality, 30, 31-58.

Gaertner, S.L., \& Dovidio, J.F. (2000). Reducing intergroup bias: the common ingroup identity model. Philadelphia, USA: Psychology Press. 
Gecas, V. (1982). The self-concept. Annual Review of Sociology, 8, 1-33.

Ghuman, P.S. (1994). Coping with two culture: British Asian and Indio-Canadian adolescents. Clevedon: Multilingual Matters Ltd.

Gilbert, P., Gilbert, J. \& Sanghera, J. (2004). A focus group exploration of the impact of izzat, shame, subordination and entrapment on mental health and service use in South Asian women living in Derby. Mental Health, Religion and Culture, 7(2), 109-130.

Green, M. C., \& Numrich, P. (2001). Religious perspectives on sexuality: a resource guide. Chicago, UL: The Park Ridge Center.

Haslam, N. (2006). Dehumanization: an integrative review. Personality and Social Psychology Review, 10(3), 252-264.

Hayes, N. (1997). Theory-led thematic analysis: Social identification in small companies. In N. Hayes (Ed.), Doing qualitative analysis in psychology (pp. 93-114). Hove: Psychology Press.

Hughes, H.L. (2003). Marketing gay tourism in Manchester: new market for urban tourism or destruction of 'gay space'. Journal of Vacation Marketing, 9(2), 152-163.

Jacobson, J. (1997). Religion and ethnicity: dual and alternative sources of identity among young British Pakistanis. Ethnic and Racial Studies, 20, 238-256.

Jamal, A. (2001). The story of Lot and the Quran's perceptions of the morality of same-sex sexuality. Journal of Homosexuality, 41, 1-88.

Jaspal, R. (2010). Identity threat among British Muslim gay men. The Psychologist, 23(8), 640-41.

Jaspal, R. \& Cinnirella, M. (2009). Fluctuating identities in inter-ethnic settings: exploring intergroup relations and identity processes through reflective accounts from British South Asians. Paper presented at BPS Social Psychology Section Annual Conference, University of Sheffield, 17th September 2009.

Jaspal, R. \& Cinnirella, M. (2010a). Coping with potentially incompatible identities: accounts of religious, ethnic and sexual identities from British Pakistani men who identify as Muslim and gay. British Journal of Social Psychology, 49(4), 849-870.

Jaspal, R. \& Cinnirella, M. (2010b). The construction of ethnic identity: insights from identity process theory. Manuscript submitted for publication.

Jaspal, R. \& Cinnirella, M. (2010c). Media representations of British Muslims and hybridised threats to identity. Contemporary Islam: Dynamics of Muslim Life, 4(3), 289-310.

Jaspal, R. \& Coyle, A. (2009). Language and perceptions of identity threat. Psychology and Society, 2(2), 150-167.

Jaspal, R. \& Coyle, A. (2010a). 'Arabic is the language of the Muslims - that's how it was supposed to be': exploring language and religious identity through reflective accounts from young British-born South Asians. Mental Health, Religion and Culture, 13(1), 17-36. 
Jaspal, R. \& Coyle, A. (2010b). 'My language, my people': language and ethnic identity among British-born South Asians. South Asian Diaspora, 2(2), 201-18.

Jaspal, R. \& Siraj, A. (in press). Perceptions of 'coming out' among British Muslim gay men. Psychology and Sexuality.

Kelman, H. C. (1997). Nationalism, patriotism, and national identity: social- psychological dimensions. In D. Bar-Tal, \& E. Staub (Eds.), Patriotism in the lives of individuals and nations (pp. 165-189). Chicago: Nelson-Hall.

Kligerman, N. (2007). Homosexuality in Islam: a difficult paradox. Macalester Islam Journal, 2(3), 55-64.

Markowe, L.A. (2002). Coming out as a lesbian. In A. Coyle \& C. Kitzinger (Eds.), Lesbian and Gay Psychology: New Perspectives (pp. 63-80). Oxford: BPS Blackwell.

Markus, H., \& Nurius, P. (1986). Possible selves. American Psychologist, 41, 954- 969.

Marques, J., Yzerbyt, V., \& Leyens, J.-P. (1988). The 'black sheep effect': extremity of judgments toward ingroup members as a function of group identification. European Journal of Social Psychology, 18, 1-16.

Modood, T., Berthoud, R., Lakey, J., Nazroo, J., Smith, P., Virdee, S. \& Beishon, S. (1997). Ethnic minorities in Britain: diversity and disadvantage. London: Policy Studies Institute.

Moscovici, S. \& Hewstone, M. (1983). Social representations and social explanations: from the 'naive' to the 'amateur' scientist. In M. Hewstone (Ed.), Attribution theory: social and functional extensions (pp. 99-125). Oxford: Blackwell.

Murray, S. O. (1997). Male actresses in Islamic parts of Indonesia and the Southern Philippines. In S. O. Murray \& W. Roscoe (Eds.), Islamic homosexualities: culture, history and literature (pp. 256-261). New York: New York University Press.

Nasir, S. (2006). Queer. In N. Ali, V.S. Kalra \& S. Sayyid (Eds.), A postcolonial people: South Asians in Britain (pp. 289-90). London: C. Hurst and Co.

Phellas, C. N. (2005). Cypriot gay men's accounts of negotiating cultural and sexual identity: a qualitative study. Qualitative Sociology Review, 1(2), 65-83.

Raj. S.D. (2000). "Who the hell do you think you are?” Promoting religious identity among young Hindus in Britain. Ethnic and Racial Studies, 23(3), 535-58.

Rayside, D. \& Wilcox, C. (eds.) (2011). Religion, Sexuality and Politics in Canada and the United States, Vancouver: UBC Press.

Richardson, J.E. (2004). (Mis)representing Islam: the racism and rhetoric of British broadsheet newspapers. Amsterdam: John Benjamins. 
Riggs, D.W. (2006). Priscilla, (White) queen of the desert: queer rights/ race privilege. Oxford: Peter Lang Publishing.

Rosenberg, M. (1984). Transient depersonalization: the loss of identity in adolescence. Paper presented at the BPS Self and Identity Conference, University College, Cardiff, July 1984.

Simon, B. (2004). Identity in modern society: a social psychological perspective. Oxford: Blackwell Publishing.

Siraj, A. (2006). On being homosexual and Muslim: conflicts and challenges. In L. Ouzgane (Ed.), Islamic masculinities (pp. 202-216). London: Zed Books.

Siraj, R. (2009). The construction of the homosexual 'other' by British Muslim heterosexuals. Contemporary Islam, 3, 41-57.

Verkuyten, M. (2005). The social psychology of ethnic identity. Hove: Psychology Press.

Vignoles, V. L., Chryssochoou, X., \& Breakwell, G. M. (2002). Evaluating models of identity motivation: self-esteem is not the whole story. Self and Identity, 1, 201-218.

Vignoles, V. L., Regalia, C., Manzi, C., Golledge, J., \& Scabini, E. (2006). Beyond self-esteem: influence of multiple motives on identity construction. Journal of Personality and Social Psychology, 90, 308-333.

Whitaker, B. (2006). Unspeakable love: gay and lesbian life in the Middle East. London: Saqi Books.

Yip, A.K.T. (1997). Gay Male Christian Couples: Life Stories. Westport, CT: Praeger.

Yip, A. K. T. (2004). Embracing Allah and sexuality? South Asian non-heterosexual Muslims in Britain. In K.A. Jacobsen \& P.P. Kumar (Eds.), South Asians in the diaspora: histories and religious traditions (pp. 294-310). Leiden: Brill.

Yip, A.KT. (2005). Queering religious texts: an exploration of British non- heterosexual Christians' and Muslims' strategies of constructing sexually-affirming hermeneutics. Sociology, 39(1), 47-65.

Yip, A.K.T. (2007). Changing religion, changing faith: reflections on the transformative strategies of lesbian, gay and bisexual Christians and Muslims. Journal for Faith, Spirituality and Social Change, 1(1), 83-95.

Wilcox, M. (2003). Coming Out in Christianity. Bloomington: Indiana University Press. 